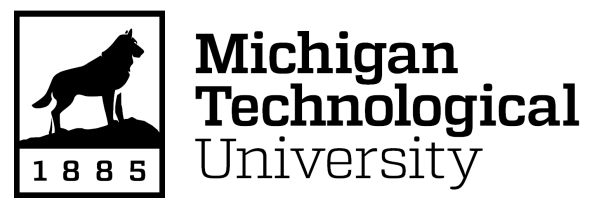

Michigan Technological University Digital Commons @ Michigan Tech

\title{
A SUSTAINABILITY-BASED PROJECT SELECTION ALGORITHM: SOCIO-TECHNICAL-ECONOMIC PROJECT SELECTION (STEPS) ALGORITHM
}

Bharathi Bhattu

Michigan Technological University, bbhattu@mtu.edu

Copyright 2016 Bharathi Bhattu

\section{Recommended Citation}

Bhattu, Bharathi, "A SUSTAINABILITY-BASED PROJECT SELECTION ALGORITHM: SOCIO-TECHNICALECONOMIC PROJECT SELECTION (STEPS) ALGORITHM", Open Access Master's Thesis, Michigan Technological University, 2016.

https://doi.org/10.37099/mtu.dc.etdr/257

Follow this and additional works at: https://digitalcommons.mtu.edu/etdr

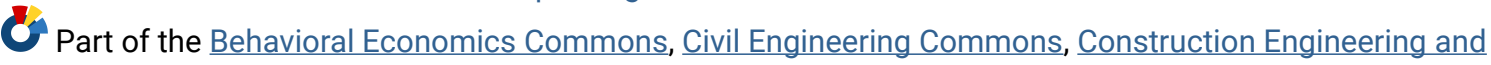
Management Commons, Econometrics Commons, Economic Theory Commons, Environmental Engineering Commons, Environmental Studies Commons, Finance and Financial Management Commons, Geotechnical Engineering Commons, Health Economics Commons, Hydraulic Engineering Commons, Other Civil and Environmental Engineering Commons, Public Economics Commons, and the Regional Economics Commons 
A SUSTAINABILITY-BASED PROJECT SELECTION ALGORITHM:

SOCIO-TECHNICAL-ECONOMIC PROJECT SELECTION (STEPS) ALGORITHM

By

Bharathi Bhattu

\begin{abstract}
A THESIS
Submitted in partial fulfillment of the requirements for the degree of MASTER OF SCIENCE

In Environmental Engineering
\end{abstract}

MICHIGAN TECHNOLOGICAL UNIVERSITY

2016

(C) 2016 Bharathi Bhattu 
This thesis has been approved in partial fulfillment of the requirements for the Degree of MASTER OF SCIENCE in Environmental Engineering.

Department of Civil and Environmental Engineering

Thesis Advisor: Dr. Brian Barkdoll

Committee Member: Dr. William Breffle

Committee Member: Dr. Zhen Liu

Department Chair: $\quad$ Dr. David Hand 


\section{TABLE OF CONTENTS}

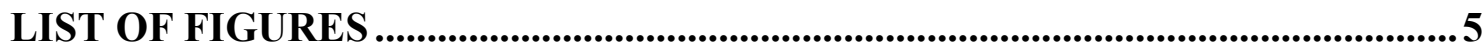

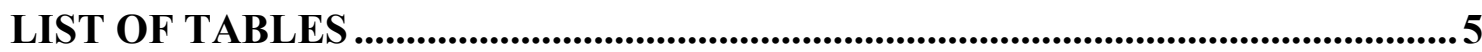

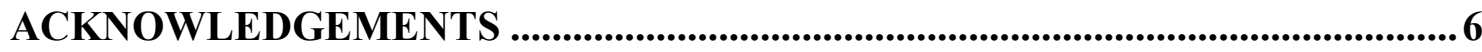

ABBREVATIONS...................................................................................................

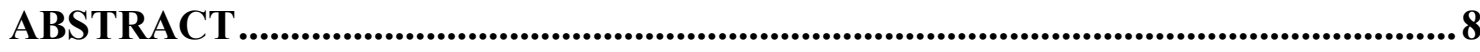

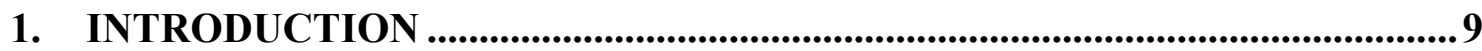

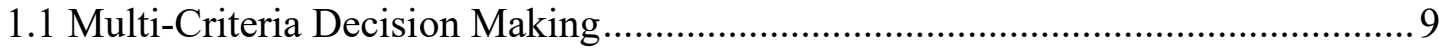

1.2 Recycled Concrete Aggregate as Riprap......................................................... 9

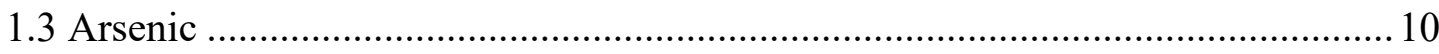

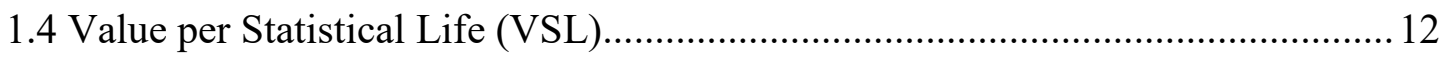

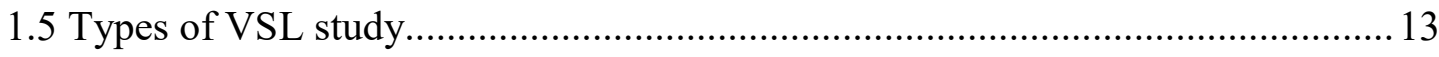

1.5.1 Stated and revealed preference methods ................................................ 14

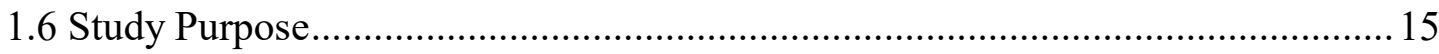

\section{SOCIO-TECHNICAL-ECONOMIC PROJECT SELECTION}

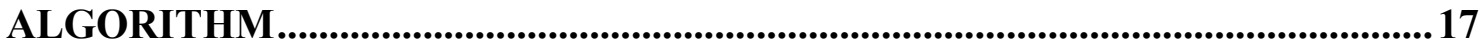

3. STEPS ALGORITHM DEMONSTRATION ..........................................18

3.1 Step 1: Environmental and Health Impacts.................................................... 19 
3.1.1 Scenario 1

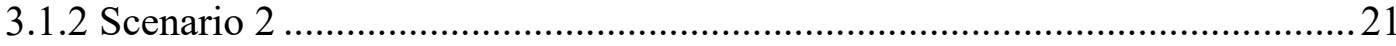

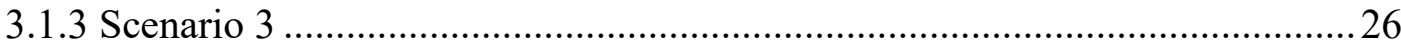

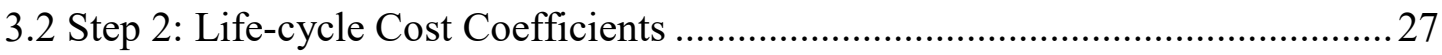

3.2.1 Scenario 1- Life-cycle cost coefficient ................................................29

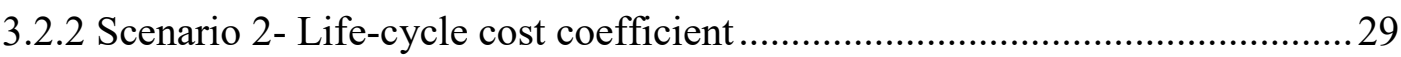

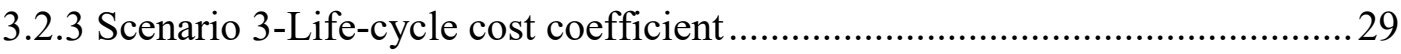

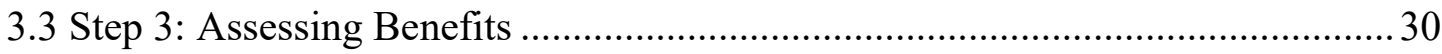

3.3.1 Estimated VSL for arsenic contamination by USEPA with adjustments ....... 30

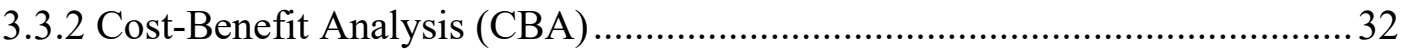

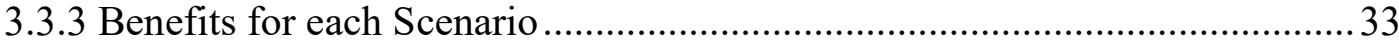

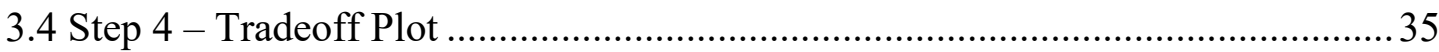

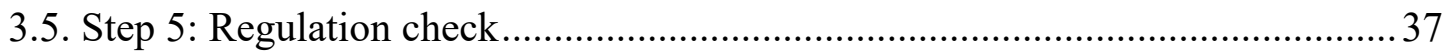

4. SUMMARY AND CONCLUSIONS ..............................................................38

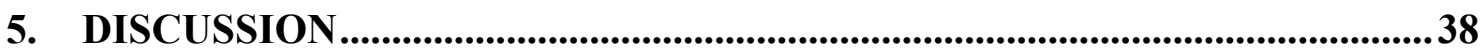

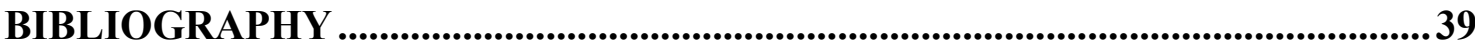

APPENDIX A- Riprap sizing method- Anderson et al. 1970...................................... 46

APPENDIX B- Effect on WTP of Household income and health risk type ...........50 


\section{LIST OF FIGURES}

Figure 1. Dose-Response analysis at various arsenic dose values

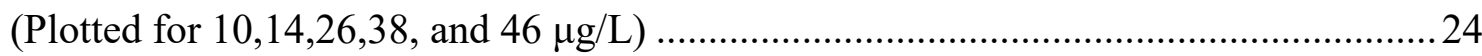

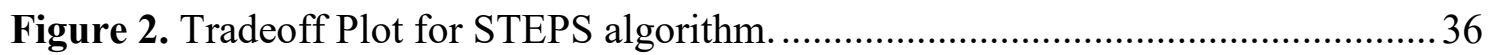

\section{LIST OF TABLES}

Table 1. Dose Response study using Sensitivity Analysis....................................... 25

Table 2. Estimation of life-cycle costs associated with Scenarios 2 and 3.................. 28

Table 3. Avoided losses calculated at $14 \mu \mathrm{g} / \mathrm{L}$ arsenic dosage for 10,000 people......... 33

Table 4. Cost-Benefit Analysis for each Scenario ....................................................... 34

Table 5. Estimated values for different aspects in STEPS Algorithm ......................... 35

\section{Appendix-A}

Table A1. Results of the bed and side slope shear stresses when $\mathrm{d}_{50}=77 \mathrm{~mm}$........... 47

Table A2. Results of the bed and side slope shear stresses when $d_{50}=2 \mathrm{~mm} \ldots \ldots \ldots \ldots \ldots . . . .49$

\section{Appendix-B}

Table B1. Mean VSLs for a 1 in 1,000,000 risk reduction across different types of health risks [Cameron et al., 2010] adjusted for modern inflation as on (\$2016) 


\section{ACKNOWLEDGEMENTS}

I would like to express my sincere gratitude to my thesis advisor, Dr. Brian Barkdoll for the continuous guidance and support during my time at Michigan Tech. He steered me in the right direction. He was always patient, encouraging, and supportive. I am also grateful for his time, ideas, effort and financial support. This work would not have been possible without his guidance.

I would like to thank Dr. William Breffle, who was involved in the validation of this thesis. He provided me with guidance and comments on my thesis which gave me the direction I needed to undertake for the economic benefits (i.e., avoided mortality losses) section in writing this report.

I would also like to thank Dr. Zhen Liu, for reviewing my thesis and giving me valuable suggestions.

Finally, I would like to thank my entire family and friends who supported me throughout my time doing research without complaining about my busy schedule. I could not have done this without their encouragement and support. 


\section{ABBREVATIONS}

$\begin{array}{ll}\text { AMR } & \text { Annual Mortality Rate } \\ \text { CBA } & \text { Cost Benefit Analysis } \\ \text { CPI } & \text { Consumer Price Index } \\ \text { CVM } & \text { Contingent Valuation Method } \\ \text { EHI } & \text { Environmental and Health Impacts } \\ \text { GPM } & \text { Gallons Per Minute } \\ \text { MCL } & \text { Maximum Contamination Level } \\ \text { NOAA } & \text { National Oceanic and Atmospheric Administration } \\ \text { RCA } & \text { Recycled concrete aggregate } \\ \text { SDWA } & \text { Safe Drinking Water Act } \\ \text { STEPS } & \text { Socio-Technical-Economic Project Selection } \\ \text { USEPA } & \text { United States Environmental Protection Agency } \\ \text { USPHS } & \text { United States Public Health Service } \\ \text { VSL } & \text { Value per statistical life } \\ \text { Willingness To Pay }\end{array}$




\begin{abstract}
Multi-dimensional aspects play a vital role in the task of project-decision making. Environmental effects are to be considered in addition to other technical and non-technical aspects in order to avoid undue environmental damage. This current work introduces a new decision-making algorithm (Socio-Technical-Economic Project Selection or STEPS) that is demonstrated with the use of RCA (recycled concrete aggregate) as riprap for slope stabilization and erosion control which leaches chemical arsenic when in contact with water. Arsenic has long been recognized for its lethal properties. The main intention of introducing this new algorithm is to use sustainability concepts of social, technical, and economic aspects to choose among several project options. The algorithm is demonstrated on three RCA scenarios to compare and select a project option considering environmental, health, life-cycle costs and benefits. The benefits of choosing a scenario are then assessed by CBA (cost-benefit analysis) through VSL (value per statistical life) and dose-response analysis. The VSL estimated by USEPA for arsenic is adjusted for inflation to be approximately $\$ 8.8$ million dollars (\$2016). The estimated VSL is then used for assessing benefits in terms of avoided mortality losses. It was found that the STEPS algorithm results in a more balanced selection rather than deciding on any criteria individually.
\end{abstract}




\section{INTRODUCTION}

\subsection{Multi-Criteria Decision Making}

In a project option selection, there are multiple selection metrics, such as cost, technical success, environmental impact, and impact on human health. A project option can be made using any of these criteria, but this may not lead to a robust selection. Usually only initial cost outlay is considered, in which an option is selected by being the least expensive option that works. In rare cases the life-cycle cost is used instead of simply the initial cost. The need to incorporate the social attitudes towards the various project options is also of paramount importance, since the users can halt the implementation of the project either due to their feeling that the project is not worth the cost, or that the environmental effects need to be considered to avoid undue environmental damage.

\subsection{Recycled Concrete Aggregate as Riprap}

Riprap, which is also known as shot rock or rubble, is a foundation laid for slope stabilization of structure with a side slope (e.g., river embankment, channel embankment) and to prevent erosion using a variety of rocks. In this project, recycled concrete aggregate (RCA) is used as riprap. Recycled concrete is basically old concrete from concrete structures such as buildings, sidewalks, roadways, and curbs. The demolished concrete undergoes processing and screening to remove leftover steel pieces, after which the concrete is made into different sizes. Usage of RCA for various purposes has been increasing in usage and lowers the cost of virgin aggregate and the negative effects of otherwise-needed disposal. RCA exhibits excellent mechanical and 
physical properties (bearing strength, freeze-thaw durability, and higher resilient modulus).

There are negative environmental impacts, however, as water from any source (precipitation, river flow, etc.) that has percolated through the field-recycled concrete aggregate comes out as contaminated leachate. The leachate can be contaminated by heavy metals such as arsenic, chromium, lead, and selenium, which have been found to exceed the maximum contaminant limit (MCL) for the drinking water standard set by United States Environmental Protection Agency (USEPA) [Chen et al., 2013]. These heavy metals are immunosuppressant and can cause cancer and various other health concerns.

\subsection{Arsenic}

Arsenic (As)causes "arsenicosis" and has long been recognized for its lethal properties resulting in high mortality and morbidity rates from cancers of the skin, bladder, and lungs [Hopenhayn et al., 1996; Smith et al., 1998; and Steinmaus et al., 2000]. There are also limited sources that show arsenic may cause cancers of the kidney, liver, and prostate. It also causes multiple organ failures caused by cardiogenic shock and pregnant women, when exposed to arsenic, have increased risk of lower respiratory tract infection and diarrhea. Treating and preventing arsenic poisoning has become a high priority. Arsenic compounds have been recognized for their lethal properties in a wide range of applications like weed-killers.

Arsenic is widely-distributed and is a ubiquitous element available in organic and inorganic forms. However, organic forms are considerably less toxic than inorganic ones. The biggest source of arsenic is the earth's crust. When subjected to erosion, water picks up the arsenic from the crust, and transfers it to plants, animals, and humans. Humans are exposed to arsenic mainly through many sources such as environmental, occupational, and medicinal. Human arsenic exposure may result in various damaging effects, such as increased mortality from multiple internal organ 
cancers such as liver, kidney, lung, bladder, and pigmentation [Engel and Smith., 1994; Tsai et al., 1999]. Other non-cancerous mortality risks include thickening of the skin, diabetes, developmental defects, hearing impairment, and adverse effects on the nervous system, heart, and circulatory systems. Although arsenic is a part of human tissue and is available within the body in trace amounts, it is not generally considered to be an essential element of human physiology.

Soluble inorganic arsenic can have immediate toxic effects as mentioned above. But there are examples which support the claim that long term exposure is dangerous. One such example is the long-term presence of inorganic arsenic in drinking water in Taiwan [Chi and Blackwell, 1968]. Long term exposure of arsenic has caused Blackfoot disease, in which the blood vessels in the lower limbs are severely damaged, resulting eventually in progressive gangrene. Also, arsenic contamination in the groundwater of Bangladesh was reported to be the largest poisoning of a human population in history [Smith et al., 2000 and Sohel et al., 2009]. These examples are sufficient to prove that arsenic toxicity is important, and it is necessary to take steps to eradicate the arsenic contamination from new sources.

The United States has known of the dangerous and detrimental effects of arsenic for a long time. The arsenic concentration in drinking water is regulated by the United States Environmental Protection Agency (USEPA). In 1942, the United States Public Health Service (USPHS) imposed a restriction of a maximum permissible concentration (MPC) of $50 \mu \mathrm{g} / \mathrm{L}$ of arsenic in drinking water. This standard was revised in 1962 by the USPHS to $10 \mu \mathrm{g} / \mathrm{L}(0.01 \mathrm{mg} / \mathrm{L})$. In1970 the USEPA was formed and the MCLs were not enforced on drinking water standards [O'Connor 2002]. The USEPA adapted this $50 \mu \mathrm{g} / \mathrm{L}$ limit under the Safe Drinking Water Act (SDWA) in 1975 and enforced this limit to all sources until October 2001, when the USEPA came up with the new arsenic standard of $10 \mu \mathrm{g} / \mathrm{L}$ for drinking water. In June 2000, the USEPA proposed a new limit of $5 \mu \mathrm{g} / \mathrm{L}$ but finally set the arsenic standard to $10 \mu \mathrm{g} / \mathrm{L}$ as USEPA believed that 10 $\mu \mathrm{g} / \mathrm{L}$ maximizes the heal risk reductions at a cost justified by benefits complying with 
the Safe Drinking Water Act regulations, $§ 1412$ (b)(6) [USEPA, 2002; US SDWA, 1886].

\subsection{Value per Statistical Life (VSL)}

Economic value of life, cost of life, or potency of life can be assigned to human beings, but there is a significant difference between statistical and identified lives. As quoted by Schelling in 1968, "It is not the worth of human life that I shall discuss, but of 'life-saving,' of preventing death. And it is not a particular death, but a statistical death." So, the statistical value of human life is the point of consideration in this context [Viscusi and Aldy, 2003].

However, the value of statistical life (VSL) concept does not estimate the value of one specific person's life, but is a tool to estimate the degree of preference/ favorability of a particular population towards reducing the risk of death which might be posed by a particular danger/ threat to the entire population. This estimate is "statistical" because it depends on future risk of death, not the certainty of death. The variation of willingness to pay (WTP) for mortality-risk reduction with age is an important, unresolved question for policy analysis. Economic theory is inclusive as to whether WTP to reduce mortality risk is expected to be lower for those with less remaining life expectancy [Hammitt, 2007]. Aggregate willingness to pay will increase if there are a predicted increased number of deaths over a period of time [USEPA, 2000].

WTP for this concept of a statistical life can now be stated as how much an entire population collectively would pay to save a single, but unspecific, life. Assume an option where a population of 50,000 people is under consideration. If each of those 50,000 people experiences a 1-in-50,000 reduction in the risk of mortality due to a newly-introduced rule/regulation, then that rule/regulation is expected to save one statistical life from premature death. Putting a monetary value on this life, let us assume that on average 50,000 people are willing to pay $\$ 100$ each on average for a specific 
risk reduction, then it can be said that the value of one statistical life can be put at $\$ 5$ million $(50,000 \times \$ 100)$. This value does not mean that an individual would accept $\$ 5$ million as an exchange for his/her certain death. What it means is that a population is willing to contribute $\$ 5$ million to eliminate a risk that is expected to kill one among them.

It is important to put a value on a population's preference of saving a statistical life because, as far as rulemaking for environmental purposes is concerned, the rules are justified by a factor called the WTP for reducing the premature mortality rate. Other benefits may also arise. The USEPA published a study which states that out of the total monetized benefits that resulted from the regulations in the Clean Air Act, 90 percent of them are from saved statistical lives [Robinson, 2007].

The complexity that comes with valuing a statistical life is that not everyone will have the same perception of risk or value risk reduction the same. These perceptions vary as a function of the extent of exposure to the risk and personal preference, and thus extent could differ vastly from person to person, be it due to the geographical location or the differences in susceptibility which results due to the factors like genetics, age, gender, and annual household income [Hammitt and Johnson, 2011]. Appendix B details how people's WTP vary due to their household income and also on the health risk type. Appendix B explains the calculations performed in this report along with factors affecting people's willingness to pay. The following section will outline the various techniques employed to evaluate the VSL and derive VSL estimates for use in policy analysis.

\subsection{Types of VSL study}

VSL serves as an estimate for reductions in mortality risk. VSL estimates are derived based on techniques which can be classified into two categories: (1) stated preference methods, and (2) revealed preference methods. Both the methods are nonmarket valuation methods that can be used to value the health benefits [Kanninen, 
2007]. Although these two types of studies can be combined while addressing similar contexts, they can be evaluated independently and should be distinguished to avoid confusing results or using estimates that might double-count the values.

\subsubsection{Stated and revealed preference methods}

Stated and revealed preference methods are the techniques that are used in situations where price-based models tend to fail and non-market valuation studies must be used. They can be used to estimate the economic values for all types of ecosystems and environmental services. As of today, stated preference is the most widely used technique, and it is also extensively used by government and educational institutions for cost-benefit analysis and as a damage cost assessment tool [USEPA, 2016]. Stated preference approaches elicit individual valuations through surveys. Several applications have been made for mortality risk reductions [e.g. Cameron and DeShazo, 2010; Tsuge et al., 2005].

The contingent valuation method (CVM) is a stated preference method which involves asking people directly about their WTP for environmental services or to hypothetically reduce the risk of death which they or someone from the community could be facing [Bar et al., 2016; Park et al., 2016; and Chestnut et al., 2012]. It is called "contingent" because the people are asked questions as a part of the survey contingent (subject to chance) on a hypothetical option. This particular method requires a large sample but it is still recommended because it is like voting, and most people have voted. People find it easier to answer familiar multiple-choice questions than open-ended questions [Hanemann, 1994] which is why a US National Oceanic and Atmospheric Administration (NOAA) panel proposed the dichotomous choice format on contingent valuation [Arrow et al., 1993]. Such as, selection of required amount of sample size for survey administration, providing information to people about the purpose of the survey and their acceptance to it, minimizing non-responses, making a report for the $\mathrm{CV}$ study with all the information (e.g., sample size, questionnaire, 
responses, and non-responses), and performing follow-up questions are a few important guidelines.

An alternative to the CVM is conjoint analysis, which is another, indirect valuation technique under the stated preference method category. Rather than asking people WTP questions directly, conjoint analysis employs choice-based questions implemented through mail surveys, internet-based surveys or by other means where attributes vary over alternatives [e.g., Cho et al., 2010; Chestnut et al., 2012; and Cameron et al., 2014]. The design of conjoint analysis includes careful experimental principles based on consumer utility theory. The parameters from such a model can be used to also obtain estimates of WTP.

The revealed preference method is an indirect method that maps or associates demand for a non-market good or service such as arsenic reduction with demand for a proxy market good or service. There are different methods by which the method can be used to estimate values, but broadly they focus on observed behavior. They include travel cost analysis, cost abatement analysis, and hedonic price analysis.

Aldy and Viscusi (2007) presented a revealed-preference VSL application based on variation in job risks by industry and worker age. The current study estimates VSLs using stated preference methods.

\subsection{Study Purpose}

The main purpose of the current article is to introduce a new decision making algorithm called STEPS (Socio-Technical-Economic Project Selection). The VSL calculated from WTP is the 'Social' aspect. The evaluation of the technical issues of soil erosion and contamination due to arsenic release comprises the 'Technical' aspect. Finally, the assessment of life-cycle costs is the 'Economic' aspect in the current study. This STEPS algorithm can be used by anyone who would like to make a decision regarding multiple project options, such as government agencies, municipalities, or private property owners. 
The STEPS algorithm is demonstrated on various decisions regarding a project to protect riverbanks from erosion using recycled concrete aggregate (RCA) riprap. The study has three proposed scenarios and is divided into two sections with the first section focusing on the environmental and health impacts while the second section provides environmental economic benefits assessment through value per statistical life (VSL).

The environmental-economic study does not focus on the economic usage of concrete but instead addresses the after-use impacts to develop taxonomy of all damages occurring to humans and to estimate benefits through the VSL for mortality risk reductions that are caused by the arsenic leaching from RCA used as riprap. The assessment of benefits in terms of avoided losses by cost-benefit analysis (CBA) is performed in the end and compared to the real costs of a program that may apply when considering a project decision for its health benefits. The environmental and environmental economic benefits assessment in this paper gives us the background on how to compare and understand different options and to be able to choose when applied during real-time project decision making situations.

The rest of the report is organized as follows, the detailed explanation of the STEPS algorithm using various steps and demonstrated through RCA as riprap on a riverbank, explained with three different scenarios. The scenarios are demonstrated by evaluating environmental and health impacts, Life-cycle costs that may that may apply for the scenarios considered. It is then followed by discussion of the past VSL estimate used by USEPA for arsenic regulation, which is adjusted for moderate inflation as well as a few recent estimates of WTP to get value per statistical life for reducing mortality risks caused mainly through cancer and heart-related illness. The adjusted and new VSL is used for assessing benefits for each scenario in terms of avoided losses. The report shows the tradeoff plot for graphical representation of the algorithm to choose a balanced scenario choice along with a check for violating any regulation followed by the summary and conclusions regarding the new algorithm approach in project-decision making and a discussion in the end. 


\section{SOCIO-TECHNICAL-ECONOMIC PROJECT SELECTION ALGORITHM}

The STEPS algorithm is a graphical method that incorporates the life-cycle costs, the environmental and health impacts, and the benefits for each project scenario considered, including the do-nothing scenario. These are plotted in such a way that the tradeoffs between scenarios are clear and thereby a decision is made more robust. This algorithm results in a decision different from a decision made by any of those three criteria individually. The STEPS algorithm steps are broadly outlined next with more details in the demonstration section following.

Step 1: Environmental and Health Impacts

Determine the environmental and health impacts and the risk of mortality due to those negative impacts that are considered to be added harm to the environment due to the course of actions involved in each project option.

Step 2: Life-Cycle costs

Calculate the life-cycle costs for each scenario under consideration (including the initial project costs plus the yearly costs throughout the project design life).

Step 3: Assessing Benefits

Determine the benefits that may result from the project implementation.

Step 4: Tradeoff Plot

Plot the compiled values to understand the project tradeoffs. Choose the option from the plot which is closest to the origin and that maximizes the project benefits.

Step 5: Regulation Check

For the chosen option, check for any violations of local regulations and take appropriate measures. 


\section{STEPS ALGORITHM DEMONSTRATION}

The demonstration project used here is a project to use RCA as riprap on riverbanks to eliminate harmful erosion due to fast-flowing river water wearing away at the riverbanks and bed for a population of 10,000. The design consists of using a geotextile cloth under riprap stones of sufficient size to resist the shear stress of the flowing water on the bed and banks. The algorithm is demonstrated on a typical river of design discharge $2 \mathrm{~m}^{3} / \mathrm{sec}$, slope of 0.010 and $3.0 \mathrm{~m}$ bottom width, a 2.5:1 (horizontal: vertical) side slope with mean sediment diameter $\left(\mathrm{d}_{50}\right)=2 \mathrm{~mm}$ sand as native sediment, and a 100 $m$ length of river embankment. It is assumed that there is a road or walkway at the river's edge that needs protecting from riverbank erosion. RCA riprap is chosen as the bank protection method.

Scenario 1 is the Do-Nothing scenario in which the river bed and banks (or embankment) are allowed to erode, thereby polluting the river resulting in ecosystem degradation, more undesirable sediment settling downstream, and loss of valuable riverside land. Scenario 2 is the RCA-Riprap scenario in which riprap is laid on the bed and banks resulting in no erosion but with the addition of arsenic leaching from the RCA stones into the river and ground water. Scenario 3 is the RCA-With-Treatment scenario in which the RCA riprap is employed but the leachate is collected and the arsenic is removed by a treatment process, there by incurring treatment costs but no environmental or human toxicity impacts. There are other possible scenarios but these three demonstrated the new algorithm sufficiently and simply. 


\subsection{Step 1: Environmental and Health Impacts}

The analysis uses Eq. (1) to understand the total environmental and health impacts $\left(E H I_{T}\right)$ that are potentially possible in each scenario due to the before and after effects of laying riprap.

$$
E H I_{T}=\frac{E H I_{e}}{E H I_{\max }}=\frac{E+Q+H}{3}
$$

Where,

$E H I_{e}=$ estimated environmental and health impacts

$E H I_{\max }=$ maximum environmental and health impacts possible

$E=$ impact to the problem site or river embankment

$Q=$ impact to the surrounding environment or river water quality

$H=$ mortality occurrence

The parameters $E, Q$ and $H$ are unit-less and the values range between 0 to 1 representing the extent of damage. Subsequent sections demonstrate $E H I_{T}$ calculated for each individual scenario. The value for $E H I_{T}$ in Eq. (1) also ranges 0 to 1, where 0 is no health impacts and 1 is severe.

\subsubsection{Scenario 1}

Placing a roadway or a walkway near a river bed is hazardous and prone to cause erosion of the embankment due to the moving water. Bank protection should be anticipated in order to prevent the erosion of the embankment by providing the proper type and amount of protection at the right locations. The absence of precautionary or necessary steps would lead to unstable slope condition and site erosion, which may 
result in sediment mixing as runoff material with the river water. This would not only result in riverbank erosion and roadway failure but also injure the health of the river into which all the eroded material enters.

In this scenario, we concentrate upon a "do-nothing" case, and explain the consequences that would eventually result. This is the scenario that assumes humans neither have any inclination towards securing and maintaining the site condition nor do they care about natural resources. This may finally result in the imbalance of the ecosystem resulting in a major environmental loss in economic terms when seen as a whole. The $E H I_{T}$ that would account in this scenario are detailed below,

$E=$ Impact to the river embankment (Loss of property due to soil erosion)

Given by, $E=\left(\right.$ Volume $\left(\mathrm{m}^{3}\right)$ soil loss due to erosion/ Total erosion volume $\left(\mathrm{m}^{3}\right)$ of the river basin possible) in Eq. (2)

$$
E=\frac{\text { Erosionloss, } m 3}{\text { Totalerosionpossible, } m 3}
$$

Since, there is no precautionary step to secure embankment, E is equal to erosion maximum $\left(E_{\max }\right)$ for Scenario 1 where the extent of erosion taking place is maximum, i.e., $E=1.0$ (see Appendix A for calculation procedure)

To obtain $Q=$ loss of river water quality and other parameters within river due to entry of eroded material from river embankment, the following is considered.

At this point, more in-depth studies are required to statistically represent the extent of impact occurring to the river water quality as a result of erosion material entry. However, if the river body is considered to be one single unit which serves the purpose of drinking water, fish and plankton survival, recreation etc., and if the potential damage occurring due to the entry of erosion material into the river makes it totally 
unfit for human use directly, the maximum contaminated river quality condition with the value of 1.0 is assigned to $Q$.

To obtain $H=$ Mortality involved as a result of "do-nothing" scenario, the following is considered:

The entry of eroded material may harm the good condition of the river embankment and river quality but may not cause mortality. The sand particles that are entering the river due to erosion can be removed easily and do not cause a potential threat to human life. Therefore, the $H$ is assigned a value of 0 .

The $E H I_{T}$ from Eq. (1) for this "do-nothing" scenario is,

$$
E H I_{T}=\frac{E H I_{e}}{E H I_{\max }}=\frac{1+1+0}{3}=0.67
$$

\subsubsection{Scenario 2}

In this scenario, the embankment is protected with RCA riprap (i.e., $E=0$ ). However, this does not solve the problem completely. Perhaps it does solve the problem of restoring the immediate site condition (embankment) and securing it from future injury, but it still is a threat to the ecological system and human health. Several laboratory and field tests have proven RCA-producing leachate to be persistent and alkaline along with the presence of heavy metals like Arsenic (As), chromium (Cr), lead $(\mathrm{Pb})$, selenium $(\mathrm{Se})$, and antimony $(\mathrm{Sb})$ and trace elements like $\mathrm{Ba}, \mathrm{Cu}, \mathrm{Ni}, \mathrm{Co}$ that have exceeded the maximum contaminant level (MCL) of USEPA standards [Chen et al., 2013].

As explained above, our prime concern in this paper is arsenic (As) which is considered to have high lethal effects when mixed with water and enters into the human 
system resulting in various health concerns. Hence, protecting the embankment using RCA riprap would involve human health impacts in addition to the environmental impacts. It is important to understand how an action can result in new problems, which might impose unintended negative effects and require additional precautionary measures to control them. To understand the extent of human health and environmental impact, and also to compare the obtained values to that of other scenarios that give us the background to realize if this scenario is efficient or not, environmental and health impacts are calculated as per Eq. (1).

As the exact amount of arsenic released from RCA is unknown at this point, for the algorithm demonstration, an arsenic dose of $14 \mu \mathrm{g} / \mathrm{L}$ is used.

To calculate the parameters, $E, Q$, and $M$ for estimating $E H I_{T}$ from Eq. (1) below, the following results:

$E=0$ as a result of securing embankment by laying riprap, and

$Q=$ Impact to the river water quality due to arsenic release from RCA.

Given by, $\mathrm{Q}=($ Arsenic $(\mu \mathrm{g} / \mathrm{L})$ entering into the river/ Maximum release of arsenic $(\mu \mathrm{g} / \mathrm{L})$ from RCA possible)

$$
Q=\frac{\frac{u g}{L} \text { entering }}{\frac{\mathrm{\mu g}}{\mathrm{L}} \mathrm{RCA} \text { possible }}
$$

As per the arsenic MCL set by USEPA of $10 \mu \mathrm{g} / \mathrm{L}, Q$ should be less than or equal to 0.045 (or $4.5 \%$ ). The arsenic dose causing $Q$ to exceed this value (i.e., 0.045 ) will impact the river water quality. Since the arsenic dosage leaching during the initial flush of fresh RCA was observed to be $223.3 \mu \mathrm{g} / \mathrm{L}$ and was later observed to drop [Chen et al., 2013] this value was considered here to be the maximum arsenic possible.

The impact to river water quality of $14 \mu \mathrm{g} / \mathrm{L}$ mentioned above, is given as,

$$
Q=\frac{14 \mu \mathrm{g} / \mathrm{L}}{223.3 \mu \mathrm{g} / \mathrm{L}}=0.060
$$


$H=$ Health impact resulting in mortality due to ingestion of arsenic contaminated river water

In order to estimate the health impact for the demonstration river, the formula is given below in Eq. (4).

$$
H=\frac{\text { baseline deaths due to As ingestion }}{\text { baseline deaths due to As and deaths including all other causes }}
$$

The overall effect on an organism when exposed to a stressor, arsenic in the current study, at various concentration values is known as the dose-response relationship. In order to estimate mortality caused as a result of arsenic contamination, a dose-response relationship is required.

There is no threshold limit for arsenic toxicity. The limit of arsenic for drinking water set by USEPA of $10 \mu \mathrm{g} / \mathrm{L}$ is still questionable as a safe drinking standard. Exposure to low-to-moderate levels (10-100 $\mu \mathrm{g} / \mathrm{L})$ of arsenic through drinking water may be associated with several of the leading causes of mortality [Meliker et al., 2007; Sohel et al., 2009]. In this study, $10 \mu \mathrm{g} / \mathrm{L}$ was used as the lower limit (LL) assuming it to be safe with zero mortality. $50 \mu \mathrm{g} / \mathrm{L}$ was used here as the upper limit (UL) in accordance with the study [Chen et al., 1988; Samadder et al., 2014] that estimated the lifetime risk of dying from various cancers is an average of 13 per 1000 persons due to consumption of drinking water containing $50 \mu \mathrm{g} / \mathrm{L}$ of arsenic at a rate of $1 \mathrm{~L} /$ day. This estimate of 13 per 1000 persons is a conservative estimate of upper-limit mortality in our dose-response study.

Using these UL and LL, a linear relationship between dose and response was used [Rothman, 1986 and Smith et al., 1992]. In addition, to avoid under and over estimates of dose-responses, we also performed a sensitivity analysis for the linearly interpolated death values by varying one factor by various amounts of $\pm 1 \%$ and $\pm 2 \%$. Sensitivity analysis for these values were performed to ensure that the estimated values do not exceed the known mortality value taken for the UL (13 per 1000). 
The number of deaths due to all other causes is represented by annual mortality rate (AMR) from US census bureau that provided the AMR as 8 persons per 1000 people for the years of 2011-2015. So the expected number of deaths due to all other causes for 10,000 would approximately be 80 persons.

From the dose-response analysis in Table 1 and Figure 1, the maximum number of deaths with an arsenic dose of $14 \mu \mathrm{g} / \mathrm{L}$ at $(+) 2 \%$ of $\mathrm{m}$ is 1.326 per 1000 (i.e., 13.26 per 10,000). The $H$ from Eq. (4) is given as,

$$
H=\frac{13.26}{13.26+80}=0.14
$$

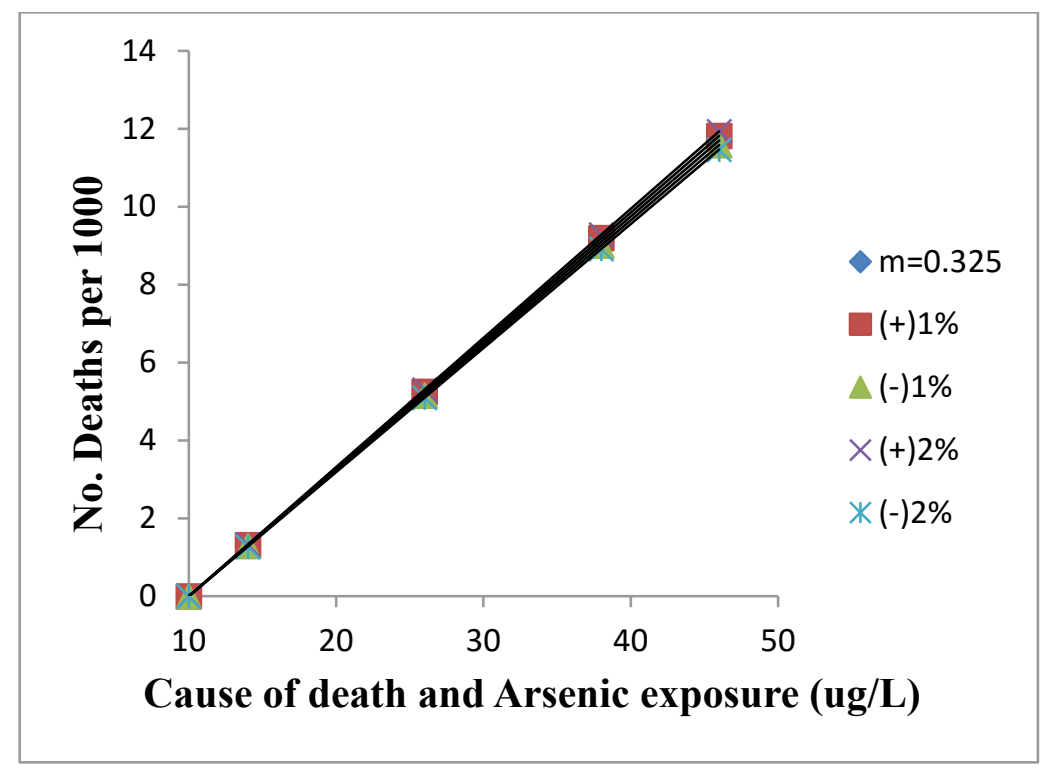

Figure 1. Dose-Response analysis at various arsenic dose values (Plotted for 10,14,26,38, and $46 \mu \mathrm{g} / \mathrm{L}$ ) 
Table 1. Dose Response study using Sensitivity Analysis

\begin{tabular}{|c|r|r|r|r|r|}
\hline \multirow{2}{*}{$\begin{array}{c}\text { Cause of death } \\
\text { and Arsenic } \\
\text { exposure (ug/L) }\end{array}$} & \multirow{2}{*}{$\mathbf{m}^{\mathbf{a}=\mathbf{0 . 3 2 5}}$} & \multicolumn{4}{|c|}{ Sensitivity Analysis ${ }^{\mathbf{b}}$ for m } \\
\cline { 3 - 6 } & & $\mathbf{( + ) 1 \%}$ & $\mathbf{( - ) 1 \%}$ & $\mathbf{( + ) 2 \%}$ & $\mathbf{( - ) 2 \%}$ \\
\hline 10 & 0.000 & 0.000 & 0.000 & 0.000 & 0.000 \\
\hline 14 & 1.300 & 1.313 & 1.287 & 1.326 & 1.274 \\
\hline 18 & 2.600 & 2.626 & 2.574 & 2.652 & 2.548 \\
\hline 22 & 3.900 & 3.939 & 3.861 & 3.978 & 3.822 \\
\hline 26 & 5.200 & 5.252 & 5.148 & 5.304 & 5.096 \\
\hline 30 & 6.500 & 6.565 & 6.435 & 6.630 & 6.370 \\
\hline 34 & 7.800 & 7.878 & 7.722 & 7.956 & 7.644 \\
\hline 38 & 9.100 & 9.191 & 9.009 & 9.282 & 8.918 \\
\hline 42 & 10.400 & 10.504 & 10.296 & 10.608 & 10.192 \\
\hline 46 & 11.700 & 11.817 & 11.583 & 11.934 & 11.466 \\
\hline 50 & 13.000 & 13.000 & 13.000 & 13.000 & 13.000 \\
\hline
\end{tabular}

${ }^{a}$ Deaths estimated (per 1000) linear interpolated slope estimates, $m=0.325$ for microgram increase of arsenic dose

'Sensitivity analysis performed to ' $\mathrm{m}$ ' values to calculate No. of deaths by driving one factor to $\pm 1 \%$, and $\pm 2 \%$ to study the dose-responses at various uncertainties

Note: Analysis performed keeping known mortality values for UL and LL constant. 
Usually, the $H$ values are region-specific. It is always advisable to perform calculations based on the data available at a particular region to get more appropriate results. Several studies on standardized mortality ratio with region and gender-specific values give guidance on value selection [e.g., Saint-Jacques et al., 2014; Meliker et al., 2007; Smith et al., 1998].

The $E H I_{T}$ from Eq. (1) for this scenario is,

$$
E H I_{T}=\frac{E H I_{e}}{E H I_{\max }}=\frac{0+0.06+0.14}{3}=0.07
$$

\subsubsection{Scenario 3}

In addition to bank protection due to RCA riprap, Scenario 3 assumes health and environmental impacts due to the release of arsenic into the river are eradicated by collecting the leachate and treating it prior to release back into the environment. Rivers are natural resources that cross legal boundaries and are held in the public trust by government and agencies. No one is given allowance to exceed the MCL set by the USEPA and contaminate human-use ecological services. By treating arsenic contamination and also embankment protection by RCA riprap, the effect on total environmental and health impacts can be accounted for as follows:

$E=0 ; Q=0 ;$ and $H=0$

i.e., $E H I_{T}$ from Eq. (1) for this scenario is given as,

$$
E H I_{T}=\frac{E H I_{e}}{E H I_{\max }}=\frac{0+0+0}{3}=0
$$




\subsection{Step 2: Life-cycle Cost Coefficients}

When seen through the perspective of ecological imbalance and other negative impacts, Scenario 3 proves to be the most desired option as it nullifies the environmental and health impacts, which is the ultimate goal of restoring any site. However, if Scenario 3 will still be the optimal choice when viewed in comparison to all scenarios in terms of life cycle costs still remains a question. This section of the report compares and discusses the total life-cycle costs that may apply for each scenario below with the calculations performed in Table 2 .

In order to compare Life cycle costs for each scenario, the cost co-efficient $\left(C_{s}\right)$ is given by,

$$
C_{\mathrm{s}}=\frac{C_{c a l}}{C_{\max }}
$$

Where, $C_{c a l}=$ life-cycle cost calculated for a scenario

$$
C_{\max }=\text { maximum life-cycle cost of all scenarios }
$$




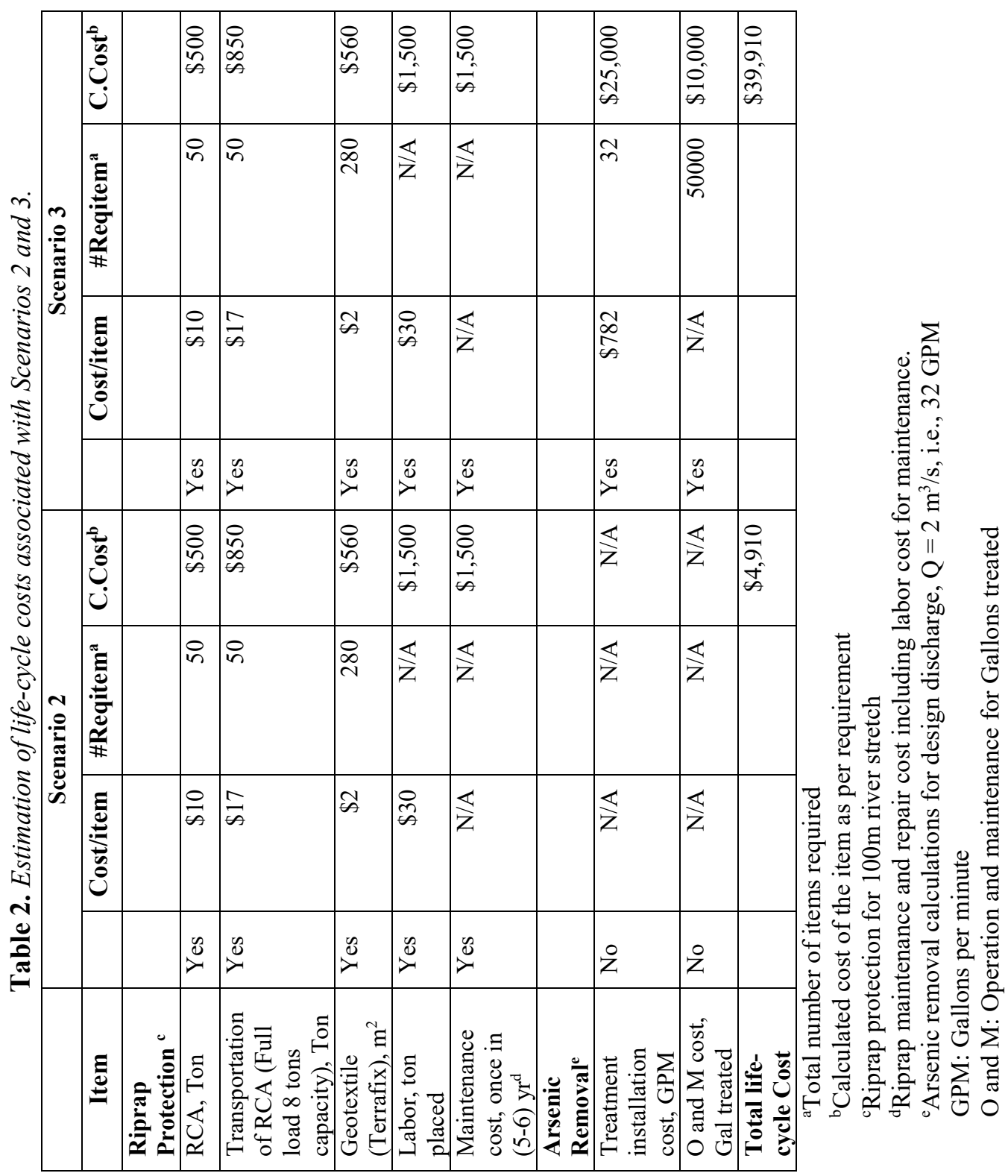




\subsubsection{Scenario 1- Life-cycle cost coefficient}

The economic cost of Scenario 1, or do-nothing, is considered zero for this analysis although there are some external costs, such as loss of property, tourism, the roadway, and in increased travel time from detouring around the washed-out road. The $C_{s}$ from Eq. (5) for Scenario 1 is,

$$
C_{s}=\frac{C_{c a l}}{C_{\max }}=\frac{\$ 0}{\$ 39,910}=0
$$

\subsubsection{Scenario 2- Life-cycle cost coefficient}

The life-cycle cost for the action of securing the embankment site is calculated and shown in Table 2 (i.e., \$4,910) for a stretch of $100 \mathrm{~m}$. Costs include riprap filter cloth, RCA transport, and placement site is clearance and preparation. Other external costs include arsenic-induced loss of human health and fish tourism.

The $C_{s}$ from Eq. (5) for Scenario 2 is,

$$
C_{s}=\frac{C_{c a l}}{C_{\max }}=\frac{\$ 4,910}{\$ 39,910}=0.12
$$

\subsubsection{Scenario 3-Life-cycle cost coefficient}

The life-cycle cost for Scenario 3 includes decontaminating river water to free it from arsenic in addition to securing river embankment by laying RCA with the parameters included in laying riprap shown in Table 2 (i.e., \$39,910).

The $C_{s}$ from Eq. (5) for Scenario 3 is,

$$
C_{s}=\frac{C_{c a l}}{C_{\max }}=\frac{\$ 39,910}{\$ 39,910}=1
$$

The numbers shown for riprap protection in Table $\mathbf{2}$ are approximate estimations as per current public rates [Riprap protection sources], and the cost for arsenic removal technology for gallons treated is taken from USEPA arsenic removal technologies and costs demonstration program for small water systems [USEPA, 2003; 
Chen et al., 2004]. The monetary costs found in this study are approximate. However, it is always advisable to perform more detailed cost estimation for a given site.

\subsection{Step 3: Assessing Benefits}

This section of the STEPS algorithm demonstration consists of assessing benefits and performing cost-benefit analysis (CBA) analysis in the current study. Unlike life-cycle costs that refer to the total amount (and/or capital) considering any action (e.g., securing embankment, de-contaminating water, etc.) for impact assessment, the benefits of the current study are in terms of avoided mortality losses by reducing As-related deaths.

To assess benefits (i.e., avoided mortality losses) in the current study when human loss is involved due to a chemical (arsenic) exposure, it is important to understand the human response at various arsenic levels from the dose-response relationship (Table 1). While avoiding mortalities by de-contaminating river water to remove arsenic itself is a benefit, in order to look at avoided mortality losses from an economic standpoint, the economic concept of Value per Statistical life (VSL) is invoked in the present study. The following section demonstrates the VSL estimates for mortality and morbidity risk reductions caused by arsenic contamination.

\subsubsection{Estimated VSL for arsenic contamination by USEPA with adjustments}

Based on historical use of VSLs, the VSL was set at \$6.1 (\$1999) million dollars by the USEPA in the cost-benefits analysis (CBA) of arsenic regulation. The value set for arsenic regulation was based from the book 'Fatal Tradeoffs' by Viscusi, (1992). This book reviewed many existing estimates from various types of risks and came up with a centralized value of around $\$ 5$ million with a range from $\$ 3-\$ 7$ million $(\$ 1990)$. 
The Viscusi data was based mainly on the data from 1982 with the underlying data averaging from 1976 [Ackerman, 2000]. From analyzing the data given by Viscusi, the USEPA arrived at a VSL of \$4.8 million (\$1990) which was later adjusted for inflation during 1999 to a figure of \$6.1 million. The USEPA continued to use the same mean VSL, adjusted for inflation, in most of its analysis of proposed regulations such as change in people's attitudes over time in health issues or changes in real income [Dockins et al., 2004].

The consumer price index (CPI) provides the data on changes in the prices that are paid by urban consumers for a representative basket of goods and services (i.e., inflation). Inflation also affects the willingness to pay that is used to derive the VSL. The consumer price index for "all urban consumers" (CPI-U) rose by 44.3 percent from 1999 to 2016 [U.S. Bureau of Labor Statistics, 2016] the value of VSL increased from \$6.1 million dollars predicted by USEPA to \$8.8 million dollars for the year 2016 due to change in the CPI. However, the conversion does not reflect other factors affecting VSL.

Considering that arsenic causes cancer and multiple-organ failure by cardiogenic shock, examining a recent study that relates to mortality risk reduction for selected causes of cancer and heart related problems using CVM, Chestnut et al. (2012) estimated a mean VSL of \$10.9 million (\$2016) for mortality risk reduction of 1 in 10,000 caused of cancer and \$9.5 million (\$2016) caused by heart attack. In contrast, conjoint analysis in the same study estimated a mean VSL of \$5.1 million (\$2016) for cancer and \$6.1 million (\$2016) for heart attack, which are less than the CVM VSLs by a factor of two within the same study. The CVM results from this study are thus comparatively near the inflation-adjusted VSL from the USEPA. 


\subsubsection{Cost-Benefit Analysis (CBA)}

For any project decision making, CBA plays a vital role. During an attempt to evaluate the durability of any action (and/or project), the best way to proceed is by attempting to identify the gains (benefits) and losses (program costs) associated with that action. If the gains exceed losses, then simple cost-benefit analysis would imply one should proceed with the action. This economic approach of comparing benefits and costs in order to validate a project decision is one other step in this algorithm demonstration. After evaluating life-cycle cost (i.e., program cost) for each scenario in Step 2, the following explanation outlines how to assess benefits and compare them to the life-cycle cost of each Scenario.

From the dose-response relationship of arsenic which gives mortality for a particular arsenic dose in Table 1 and VSL estimate for arsenic by the USEPA, the benefits in terms of avoided losses (AL) are given by,

$$
\mathrm{AL}=\text { mortality } \mathrm{x} \text { VSL }
$$

For demonstration purpose, considering arsenic mortality at $14 \mu \mathrm{g} / \mathrm{L}$ from the dose-response analysis (Table 1) and from the VSL by the USEPA for arsenic after adjustment to inflation from the above literature which is $\$ 8.8$ million, the avoided losses from Eq. (6) are given in Table 3.

From Table 3, maximum avoided losses $\left(A L_{\max }\right)$ are $\$ 117$ million. For all values of AL from Table 3 when considered for comparing to the life-cycle costs (from the STEPS Algorithm), the CBA analysis gives benefits values that are orders of magnitude higher than the total life-cycle costs essential for removing arsenic from the river water which is $\$ 39,910$ in Scenario 3 to bring the environmental and health impacts to zero. Even saving one life from arsenic would justify the most costly program by orders of magnitude, demonstrated in the next section. 
Table 3. Avoided losses calculated at $14 \mu \mathrm{g} / \mathrm{L}$ arsenic dosage for 10,000 people.

\begin{tabular}{|c|r|r|}
\hline Factor 'm' & \multicolumn{1}{|c|}{ Mortality } & \multicolumn{1}{|c|}{ AL } \\
\hline 1 & 13 & $\$ 114$ \\
\hline$(+) 1 \%$ & 13.13 & $\$ 115$ \\
\hline$(-) 1 \%$ & 12.87 & $\$ 113$ \\
\hline$(+) 2 \%$ & 13.26 & $\$ 117$ \\
\hline$(-) 2 \%$ & 12.74 & $\$ 112$ \\
\hline
\end{tabular}

Note: Avoided losses expressed in millions

\subsubsection{Benefits for each Scenario}

In order to estimate benefits or avoided mortality losses and to evaluate the validity of selecting a scenario in this demonstration project, estimated mortality risk data and value per statistical life is required. Not all scenarios may result in death. Considering the current project of using RCA as riprap, the risk of mortality occurs only in Scenario 2 but not in Scenarios 1or 3 as explained in Section 3.1 and therefore, the calculations are performed by adapting an alternative approximation method to estimate benefits and compared to life-cycle costs concerning each Scenario in Table 4.

Eq.(7) is an indirect way to calculate the life-cycle cost coefficient $\left(C_{S}\right)$ along with the maximum avoided losses $\left(A L_{\max }\right)$ value found from Eq. (6) for an arsenic dose of $14 \mu \mathrm{g} / \mathrm{L}$ when there is no direct way to statistically represent benefits for each scenario,

$$
A L_{s}=C_{s} \times A L_{\max }
$$

\subsubsection{Scenario 1- Avoided Losses}

In Scenario 1, which has zero life-cycle cost and $C_{s}$, the benefits from Eq. (7) are given as,

$$
\mathrm{AL}_{\mathrm{s}}=\mathrm{C}_{\mathrm{s}} \times \mathrm{AL}_{\max }=0 \times \$ 117 \text { million }=\$ 0
$$




\subsubsection{Scenario 2- Avoided Losses}

Scenario 2 which has life-cycle cost of $\$ 4,910$ and $C_{s}$ value of 0.09 , the avoided losses from Eq. (7) are given by

$$
\mathrm{AL}_{\mathrm{s}}=\mathrm{C}_{\mathrm{s}} \times \mathrm{AL}_{\max }=0.12 \times \$ 117 \text { million }=\$ 14 \text { million }
$$

\subsubsection{Scenario 3- Avoided Losses}

For scenario 3 with life-cycle cost of $\$ 39,910$ and $C_{s}$ value of 1 , the avoided losses from Eq. (7) are,

$$
\mathrm{AL}_{\mathrm{s}}=\mathrm{C}_{\mathrm{s}} \times \mathrm{AL}_{\max }=1 \times \$ 117 \text { million }=\$ 117 \text { million }
$$

Table 4. Cost-Benefit Analysis for each Scenario

\begin{tabular}{|c|c|c|}
\hline & $\begin{array}{c}\text { Life-cycle } \\
\text { costs }\end{array}$ & Avoided losses $^{\mathbf{a}}$ \\
\hline Scenario 1 & $\$ 0$ & $\$ 0$ \\
\hline Scenario 2 & $\$ 4,910.00$ & $\$ 14$ million \\
\hline Scenario 3 & $\$ 39,910.00$ & $\$ 117$ million \\
\hline
\end{tabular}

${ }^{a}$ Avoided losses considered here only for an arsenic dosage of $14 \mu \mathrm{g} / \mathrm{L}$.

The comparison of life-cycle costs and benefits for each scenario from Table 4. gives the actual costs of Scenario 3 associated with an arsenic treatment plant installation and $\mathrm{O}$ and $\mathrm{M}$ that help to avoid losses up to $\$ 11.7$ million as mentioned in Table 4. for an arsenic concentration of $14 \mu \mathrm{g} / \mathrm{L}$ alone. Avoided losses (i.e., benefits) increase when the calculations are performed for the higher arsenic dosage from the dose-response analysis using Eq. (6).

After following Steps 1, 2, and 3 of the STEPS algorithm demonstration through RCA as riprap in evaluating the environmental and health impact values, life-cycle costs and benefits that may apply for each scenario, it is now important to make a decision by selecting a scenario from the three listed scenarios (Scenarios 1, 2, and 3). 


\subsection{Step 4 - Tradeoff Plot}

The three Scenarios demonstrated in this riprap project are three options which are to be validated and decided on. This section of the current study shows data compilation for all the evaluated values in one table to compare and come up with a most viable option.

Estimated values for $E H I_{T}$, life-cycle costs, $C_{\mathrm{s}}$ and benefits $(A L)$ are listed in Table 5. below for a better understanding the differences in values for each scenario.

Table 5. Estimated values for different aspects in STEPS Algorithm

\begin{tabular}{|c|r|r|r|}
\hline & Scenario 1 & Scenario 2 & Scenario 3 \\
\hline EHI & $\mathbf{0 . 6 7}$ & $\mathbf{0 . 0 7}$ & $\mathbf{0 . 0 0}$ \\
\hline Costs $\mathbf{( \$ )}$ & $\mathbf{\$ 0 k}$ & $\mathbf{\$ 4 . 9 K}$ & $\mathbf{\$ 3 9 . 9 K}$ \\
\hline C $_{\text {s }}$ & $\mathbf{0 . 0 0}$ & $\mathbf{0 . 1 2}$ & $\mathbf{1 . 0 0}$ \\
\hline Benefits (\$) & $\mathbf{\$ 0 k}$ & $\mathbf{\$ 1 , 4 0 0 K}$ & $\mathbf{\$ 1 1 7 , 0 0 0 K}$ \\
\hline
\end{tabular}

It can be seen from Figure 2 that the scenario closest to the origin of the Tradeoff Plot (Scenario 2) is selected since it results in the most balanced option. Selection based on low cost would result in the selection of Scenario 1 and selection only by environmental and health impacts $\left(E H I_{T}\right)$ would result in the selection of Scenario 3.

The Tradeoff Plot can aid decision makers in deciding if project budgets are sufficient to accomplish health and environmental objectives or if additional funds are required. Alternatively, for the budget available currently, the health and environmental impacts can be determined. 


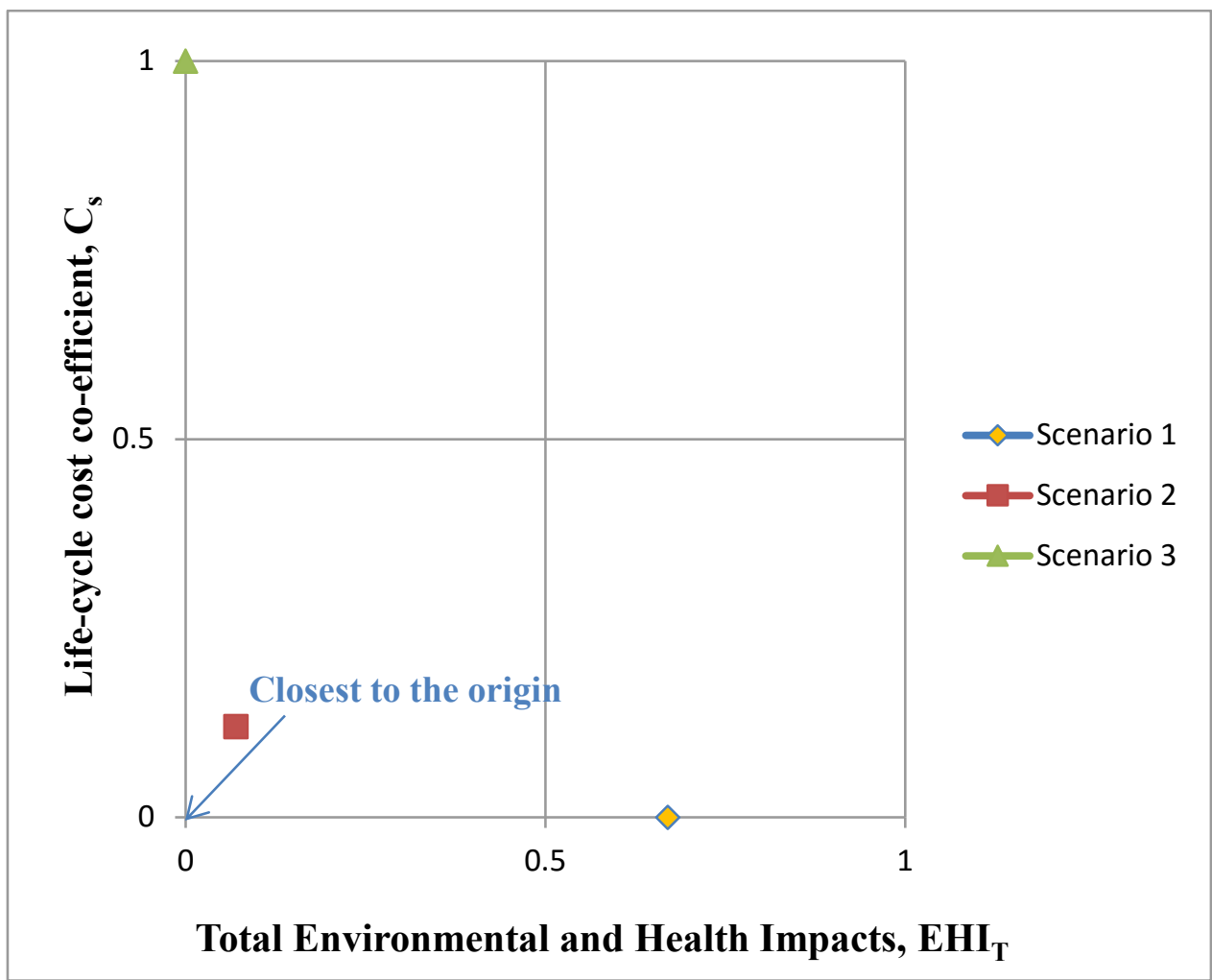

Figure 2. Tradeoff Plot for STEPS algorithm. 


\subsection{Step 5: Regulation check}

Scenario 2 was chosen by the STEPS algorithm, however, the MCL set by EPA for arsenic was slightly violated since $14 \mathrm{ug} / \mathrm{L}$ was greater than the MCL of $10 \mathrm{ug} / \mathrm{L}$. Therefore appropriate action is required. The arsenic leaching from RCA was observed to drop (223.3 $\mu \mathrm{g} / \mathrm{L}$ to $56.6 \mu \mathrm{g} / \mathrm{L})$ after few washes is a good sign [Chen et al., 2013]. It is therefore suggested that the RCA be washed until the arsenic concentration is below the MCL prior to application.

When the arsenic coming from RCA violates the MCL up to a great extent such that washing RCA alone does not solve the issue, the STEPS algorithm then suggests choosing Scenario 3 in which the river water is treated to de-contaminate arsenic to ensure no regulation is violated resulting in environmental and health damage, which is of higher importance in comparison to other aspects. 


\section{SUMMARY AND CONCLUSIONS}

The new project option selection sustainability-based algorithm and its demonstration on the use of recycled concrete aggregate for use as riprap on riverbanks for erosion protection yield the following results:

1. Project option selection based on initial cost alone neglects life cycle costs and environmental/health considerations.

2. Project option selection based only on costs can results in environmental and health damage.

3. Project option selection based only on environmental and health considerations can be prohibitively costly.

4. The newly-proposed STEPS algorithm incorporating life-cycle costs, technical aspects, and environment and health aspect results in the most balance project option selection.

5. The newly proposed STEPS algorithm is suggested for use.

\section{DISCUSSION}

The newly-proposed STEPS algorithm incorporates initial costs, life-cycle costs, environmental and health impacts, and benefits and is, therefore, more robust than other project selection algorithms. It assumes an equal weighting between these criteria. There may be cases, however, that is desired to weight one of these aspects more than the others.

The demonstration project used here consisting of using RCA as riprap for riverbank protection was chosen to investigate this relatively new technology. The results may vary for other projects, however. The costs, environmental, and health values used here are estimates and may not be directly applicable for other projects. It is best to get actual costs from local contractors. Environmental impacts and health implications should be determined by local data as well. 


\section{BIBLIOGRAPHY}

Ackerman, Frank. (2000). "High Risk Economics: Gambling on Cost-Benefit Analysis for Arsenic Standards."Comments submitted to the U.S. Environmental Protection Agency, August 2000.

Aldy, J.E. and Viscusi, W.K. (2007). "Age differences in the value of statistical life: Revealed preference evidence."Review of Environmental Economics and Policy $1,241-260$.

Anderson, A.G.; A.S. Paintal; and J.T. Davenport. (1970).“Tentative Design Procedure for Riprap Lined Channels."NCHRP Report 108. National Cooperative Highway Research Program, Highway Research Board, National Research Council, Washington DC.

Arrow K.J., Solow R.S., Learner E., Portney P., Rodner R., and Schuman H. (1993) “Report of the NOAA-panel on contingent valuation."Fed. Regist. 58(10):46014614.

Bar, P., Becker, N. and Segev, M.(2016).'Sand dunes management: a comparative analysis of ecological versus economic valuations applied to the Coastal region in Israel” Reg Environ Change 16: 941. doi:10.1007/s10113-015-0808-z

Cameron, T.A., DeShazo, J. R. and Ryan, B. (2014) "Willingness to Pay for Public Health Policies to Treat Illnesses”, Journal of Health Economics, November.

Cameron, T. A., DeShazo, J. R., and Johnson, E. H. (2010). "Willingness to Pay for Health Risk Reductions: Differences by Type of Illness," Presented at the Third 
Biennial Conference of the American Society of Health Economists, Ithaca, NY, June 20-23, 2010a.

Cameron, T. A., and J. R. DeShazo. 2010. "Differential Attention to Attributes in Utility-theoretic Choice Models."Journal of Choice Modeling 3 (3): 73-115.

Chen, A. S., L. Wang, J. L. Oxenham, and Condit, W. E.(2004). "Capital costs of arsenic removal technologies."USEPA arsenic removal technology demonstration program round 1. U.S. Environmental Protection Agency, Washington, D.C., EPA/600/R-04/201 (NTIS PB2005-102046).

Chen, C. J., Kuo, T. L., and Wu, M. M. (1988).“Arsenic and cancers” (letter). Lanceti: 414-415 (1988).

Chen J., Tinjum, J.M., and Edil, T.B. (2013). "Leaching of Alkaline Substances and Heavy Metals from Recycled Concrete Aggregate Used as Unbound Base Course", Journal of Transportation Research Record, 2349, pp. 81-90.

Chestnut, L.G. and Rowe, R.D. and Breffle, W.S. (2012). "Economic Valuation of Mortality-Risk Reduction: Stated Preference Estimates from the United States and Canada."Contemporary Economic Policy, 30(3),399-416.

Cameron, T. A., J. R. DeShazo, and E. H. Johnson. "Willingness to Pay for Health Risk Reductions: Differences by Type of Illness," Presented at the ThirdBiennial Conference of the American Society of Health Economists, Ithaca, NY, June 20-23, 2010a. "The Effect of Children on Adult Demandsfor Health-Risk Reductions." Journal of Health Economics, 29(3), 2010b, 364-76. 
Chi, I.C. and Blackwell, R.Q. (1968).“A controlled retrospective study of blackfoot disease, an endemic peripheral gangrene disease in Taiwan." Am J Epidemiol. 88:7-24.

Cho, Y., Easter, K. W. and Konishi, Y. (2010)."Economic evaluation of the new U.S. arsenic standard for drinking water: A disaggregate approach."Water Resource. Res., 46, W10527, doi:10.1029/2009WR008269.

Dockins, C., Maguire, K., Simon, N., and Sullivan, M. (2004). "Value of Statistical Life Analysis and Environmental Policy: A White Paper", U.S. Environmental Protection Agency, National Center for Environmental Economics, April.

Engel, R.R. and Smith, A.H. (1994). "Arsenic in drinking water and mortality from vascular disease: an ecologic analysis in 30 counties in the United States." Arch Environ Health, 49:418-427.

Hammitt, J.K. and Robinson, L.A. (2011) "The Income Elasticity of the Value per Statistical Life: Transferring Estimates between High and Low Income Populations," Journal of Benefit-Cost Analysis 2(1), Article 1.

Hammitt, J. K. (2007). "Valuing Changes in Mortality Risk: Lives Saved Versus Life Years Saved." Review of Environmental Economics and Policy, 1(2), 228-40.

Hanemann WM (1994) "Valuing the environment through contingent valuation". $J$ Econ Perspect., 8:19-43.

Hopenhayn-Rich C., Biggs, M.L., Fuchs, A, Bergoglio R, Tello E.E., Nicolli, H. and Smith, A.H. (1996)."Bladder cancer mortality associated with arsenic in drinking water in Argentina."Epidemiology7:117-124. 
Kanninen, B. J. (2007). "Valuing Environmental Amenities Using Stated Choice Studies.” Dordrecht: Springer.

Meliker, J.R., Wahl, R.L., Cameron, L.L., and Nriagu, J.O. (2007). “Arsenic in drinking water and cerebrovascular disease, diabetes mellitus, and kidney disease in Michigan: a standardized mortality ratio analysis."Environmental Health, 6, 4.

O’Connor, J.T. (2002). “Arsenic in Drinking Water.”Water Engineering and Management.149: 45-47

Park, S.-Y.; Lim, S.-Y.; and Yoo, S.-H. (2016).“The Economic Value of the National Meteorological Service in the Korean Household Sector: A Contingent Valuation Study." Sustainability, 8, 834.

Riprap protection: Estimated Life-cycle costs sources (as on 08/16/2016)

Riprap material cost and transportation cost.

(Available at :http:/wirelessestimator.com/content/industryinfo/702)., Erosion control blanket (terrafix 270R).

(Available at :http://www.coldstreamconcrete.com/products/geotextile/)

Robinson, L. A. (2007). "Policy Monitor: How US Government Agencies Value Mortality Risk

Reductions."Review of Environmental Economics and Policy, Vol. 1, Issue 2, pp. 283299.

Rothman, K. J. (1986)“Modern Epidemiology.” Little, Brown and Company, Boston.

Saint-Jacques, N., Parker, L., Brown, P., and Dummer, T.J. (2014).“Arsenic in drinking water and urinary tract cancers: a systematic review of 30 years of 
epidemiological evidence."Environ Health; 13:44. doi: 10.1186/ 1476-069X-1344, PMID:24889821.

Samadder, S.R., Nagesh Kumar, D., and Holden, N.M. (2014). “An empirical model to predict arsenic pollution affected life expectancy" Popul Environ36:219. doi:10.1007/s11111-014-0212-5

Smith AH, Hopenhayn-Rich C, Goeden HM, Hertz-Picciotto I, Duggan HM, Wood R, Kosnett MJ, Smith MT. (1992). "Cancer risks from arsenic in drinking water." Environmental Health Perspectives.97:259-267. doi: 10.1289/ehp.9297259.

Smith, A.H., Goycolea, M., Haque, R., and Biggs, ML. (1998). "Marked increase in bladder and lung cancer mortality in a region of Northern Chile due to arsenic in drinking water."Am J Epidemiol, 147:660-669.

Smith, A.H., Lingas, E.O., and Rahman, M. (2000). "Contamination of drinking-water by arsenic in Bangladesh: a public health emergency". Bulletin of the World Health Organization.78 (9): 1093-1103.

Sohel, N., Persson, L. A., Rahman, M., Streatfield, P. K., Yunus, M., Ekstro“m, E. C., and Vahter, M. (2009). "Arsenic in drinking water and adult mortality: a population-based cohort study in rural Bangladesh."Epidemiology. 20, 824-830.

Steinmaus, C., Moore, L., Hopenhayn-Rich, C., Biggs, M.L. and Smith, A.H. (2000). "Arsenic in drinking water and bladder cancer." Cancer Invest 2000, 18:174182.

Tsai, S-M, Wang, T-N, and Ko, Y-C (1999). "Mortality for certain diseases in areas with high levels of arsenic in drinking water." Arch Environ Health, 54:186-193. 
Tsuge, T., Kishimoto, A. and Takeuchi, K. (2005). "A Choice Experiment Approach to the Valuation of Mortality." Journal of Risk and Uncertainty, 31(1), 73-95.

US Bureau of Labor Statistics (2016), (Available at: http://www.bls.gov/home.htm) accessed on 09/26/2016.

US Census Bureau (2016), (Available at: http://www.census.gov/en.html) accessed on $08 / 12 / 2016$.

USEPA (2000). "Guidelines for Preparing Economic Analyses.” U.S. Environmental Protection Agency Office of the Administrator, EPA 240-R-00-003

USEPA. 2002. "Arsenic in Drinking Water Rule Economic Analysis." 815-R-00-026.

USEPA (2003). “Arsenic treatment technology evaluation handbook for small systems." Rep. USEPA 816-R-03-014, U.S. Environmental Protection Agency, Off. of Water, Washington, D. C.

USEPA (2016). "Valuing mortality risk reductions for policy: a meta-analytic approach." Prepared by the U.S. Environmental Protection Agency's Office of Policy, National Center for Environmental Economics for review by the EPA's Science Advisory Board, Environmental Economics Advisory Committee, February.

US SWDA (1986). United States. Pub.L. 99-359; 100 Stat. 642. "Safe Drinking Water Act Amendments of 1986." 1986-06-19.

Viscusi, W.K. (1992). "Fatal Tradeoffs Public and Private Responsibilities for Risk." New York: Oxford UP, USA. 
Viscusi, W. K. and Joseph E. A. (2003). "The Value of a Statistical Life: A Critical Review of Market Estimates throughout the World," Journal of Risk and Uncertainty, 27(1). 


\section{APPENDIX A \\ (Riprap sizing method- Anderson et al. 1970)}

Assumed trapezoidal river basin conditions

River discharge, $\mathrm{Q}=2 \mathrm{~m}^{3} / \mathrm{sec}$

Slope $=0.010$

River basin Bottom width, $\mathrm{a}=3.0 \mathrm{~m}$

Side slope, $\mathrm{m}=2.5(2.5$ horizontal: 1 vertical $)$

\section{Riprap Protection}

Anderson et al. (1970) model was used to estimate the size of RCA (crushed rock) laid as riprap to protect trapezoidal roadside river embankment from erosion.

Initially selecting a median rock size $\mathrm{d}_{50}=50 \mathrm{~mm}$

The angle of repose, $\phi=42.02^{\circ}$

Note: Estimation of Angle of Repose with respect to median rock size $\left(\mathrm{d}_{50}\right)$ for crushed rock riprap demonstrated by Anderson et al. (1970) model.

Side slope, $\theta=\tan ^{-1}(1 / 2.5)=0.38 \mathrm{rad}=21.80$ degrees

Estimating tractive force ratio:

$$
\begin{aligned}
K_{r} & =\sqrt{1-\frac{\sin ^{2} \theta}{\sin ^{2} \phi}} \\
\mathrm{K}_{\mathrm{r}} & =0.98
\end{aligned}
$$

\section{Estimating critical shear stress on bed and side slope}

Critical shear stress on bed, $(\tau)_{\mathrm{oc}}=4 \mathrm{~d}_{50}=1.01 \mathrm{lb} / \mathrm{ft}^{2}=48.4 \mathrm{~N} / \mathrm{m}^{2}$

Critical shear stress on side slope, $(\tau)_{{ }_{o c}}{ }^{\mathrm{w}}=\mathrm{K}_{\mathrm{r}}(\tau)_{\mathrm{oc}}=47.3 \mathrm{~N} / \mathrm{m}^{2}$ 


\section{Solving Manning's equation for normal depth}

(Metcalf and Eddy Inc., 1881)

$\frac{A^{5 / 3}}{p^{2 / 3}}=\frac{\left(y_{0}\left(3.0+2.5 y_{0}\right)\right)^{5 / 3}}{\left(3.0+2 \sqrt{1+2.5^{2}} y_{0}\right)^{2 / 3}}=\frac{n Q}{S^{1 / 2}}:$

Estimating normal depth, $\mathrm{y}_{\mathrm{o}}$ from the above equation using the assumed conditions and Manning's $\mathrm{n}=0.04 \mathrm{~d}_{50}{ }^{1 / 6}=0.032$

This gives, $\mathrm{y}_{\mathrm{o}}=0.41 \mathrm{~m}$

Estimating the top width of the river basin from $b=a+\left(2 \mathrm{my}_{\mathrm{o}}\right)=5.05 \mathrm{~m}$

Basin Area, $\mathrm{A}=1.65 \mathrm{~m}^{2}$

Basin Parameter, $\mathrm{P}=5.21 \mathrm{~m}$

Finding $\mathrm{R}=\mathrm{A} / \mathrm{P}=0.32 \mathrm{~m}$

\section{Evaluating maximum shear stress on bed and side slope}

Maximum shear stresses on bed, $(\tau)_{\mathrm{om}}=1.5 \gamma \mathrm{RS}$

Maximum shear stresses on side slope, $(\tau)_{\mathrm{om}}{ }^{\mathrm{w}}=1.2 \gamma \mathrm{RS}$

Where, $\gamma=9810 \mathrm{~N} / \mathrm{m}^{2}$

The initially-selected riprap size is too small as the estimated maximum shear stresses exceed critical values. After trial and error, the values in Table A1 are obtained when the crushed rock size is $77 \mathrm{~mm}$ ( $3 \mathrm{in})$,

Table A1. Results of the bed and side slope shear stresses when $d_{50}=77 \mathrm{~mm}$.

\begin{tabular}{|l|l|l|}
\hline & Critical & Maximum \\
\hline Bed & 48.4 & 46.6 \\
\hline Side slope & 47.3 & 37.3 \\
\hline
\end{tabular}

Estimated riprap size for ensuring slope erosion protection is $d_{50}=77 \mathrm{~mm}$ (or) 3 inches. 


\section{No Riprap Protection}

In order to estimate total erosion, the river embankment with $\mathrm{d}_{50}=2 \mathrm{~mm}$ (sand) along with the above-assumed conditions and no riprap protection is assumed and the river bottom width was varied to find the total volume loss in erosion.

Angle of repose, $\phi=45^{\circ}$ for sand

Side slope, $\theta=\tan ^{-1}(1 / 2.5)=0.380506377 \mathrm{rad}=21.8$ degrees

Estimating tractive force ratio:

$$
K_{r}=\sqrt{1-\frac{\sin ^{2} \theta}{\sin ^{2} \phi}}
$$

$\mathrm{K}_{\mathrm{r}}=0.97$

\section{Estimating critical shear stress on bed and side slope}

Critical shear stress on bed, $(\tau)_{\mathrm{oc}}=4 \mathrm{~d}_{50}=0.027 \mathrm{lb} / \mathrm{ft}^{2}=1.26 \mathrm{~N} / \mathrm{m}^{2}$

Critical shear stress on side slope, $(\tau)_{\mathrm{oc}}{ }^{\mathrm{w}}=\mathrm{K}_{\mathrm{r}}(\tau)_{\mathrm{oc}}=1.22 \mathrm{~N} / \mathrm{m}^{2}$

Varying river basin bottom width, $a$, in the above-mentioned Manning's equation until maximum shear stresses are less than critical shear stresses

\section{Evaluating maximum shear stress on bed and side slope}

Maximum shear stresses on bed, $(\tau)_{\mathrm{om}}=1.5 \gamma \mathrm{RS}$

Maximum shear stresses on side slope, $(\tau)_{\mathrm{om}}{ }^{\mathrm{w}}=1.2 \gamma \mathrm{RS}$

where, $\gamma=9810 \mathrm{~N} / \mathrm{m}^{2}$

The condition is solved when $a=1064 \mathrm{~m}$ and $\mathrm{Y}_{\mathrm{o}}=0.008 \mathrm{~m}$

Estimating top width of the river basin from $b=a+\left(2 \mathrm{my}_{\mathrm{o}}\right)=1064.04 \mathrm{~m}$ 
Basin Area, $\mathrm{A}=8.52 \mathrm{~m}^{2}$

Basin Perimeter, $\mathrm{P}=1064.05 \mathrm{~m}$

$\mathrm{R}=\mathrm{A} / \mathrm{P}=0.008 \mathrm{~m}$

The Critical and Maximum shear stresses of bed and side slope when $a=1064 \mathrm{~m}$ are given in Table A2 below,

Table A2. Results of the bed and side slope shear stresses when $d_{50}=2 \mathrm{~mm}$.

\begin{tabular}{|l|l|l|}
\hline & Critical & Maximum \\
\hline Bed & 1.25 & 1.18 \\
\hline Side slope & 1.22 & 0.94 \\
\hline
\end{tabular}

Total area lost in erosion: $\mathrm{A}_{2}-\mathrm{A}_{1}=6.87 \mathrm{~m}^{2}$

Total erosion for $100 \mathrm{~m}$ stretch $=6.87 \mathrm{~m}^{2} \times 100 \mathrm{~m}=687 \mathrm{~m}^{3}$

To calculate $E=$ Loss of property in erosion from Eq. (2),

$E=($ Volume loss due to erosion/ Total erosion volume of the river basin possible)

i.e., $E=\frac{\text { Erosionloss, } m 3}{\text { Totalerosionpossible, } m 3}$

Erosion loss in this present condition $=687 \mathrm{~m}^{3}$

Total Erosion possible $=687 \mathrm{~m}^{3}$ (in the extreme condition of embankment has the natural sediment ofd $\mathrm{s}_{50}=2 \mathrm{~mm}$.

Therefore, we get $E=1$

\section{Appendix A- References}

Metcalf \& Eddy Inc. 1981. Wastewater engineering: collection and pumping of wastewater. McGraw-Hill, New York. 


\section{APPENDIX B \\ (Effect on WTP of Household income and health risk type)}

In the estimation of WTP, household income plays a vital role along with many other variables. Income tends to influence willingness to pay positively and significantly [Hokby et al., 2003]. People with higher income are willing to pay more for reducing the risk of mortalities, whereas people with lower income tend to have a lower WTP, even though they desire to reduce more risk. The WTP percent change in regard to income elasticity (e) can be explained using Eq. (B1),

$$
\varepsilon_{\mathrm{y}}{ }^{\mathrm{WTP}}=\frac{\% \Delta \text { inWTP }}{\% \Delta \text { inIncome }}
$$

Where, $\varepsilon_{\mathrm{y}}{ }^{\text {WTP }}$ equals the percent change in willingness to pay given a one given a one percent change in real household income. Census data from 1990 to 2014 show that the real median household income which considers the effect of inflation in the United States, increased by $7.3 \%$ (in \$2014). People's willingness to pay shows an exponential upward trend for change in real household income across various income elasticity values. In order to adjust the past estimates of VSLs with respect to a U.S. per capital household income change, and make them applicable to present-world scenarios of changed conditions, researchers have derived a variety of income elasticity estimates. In the paper given by Chestnut et al. (2012), the elasticity of WTP with respect to income was 0.4 in the U.S. and 0.5 in Canada to estimate changes in VSLs for mortality-risk reductions for cancer and heart attack risks, respectively. In contrast, Cameron et al. (2010) estimated the income elasticity to be about 1.1 for WTP change in risk reductions of different types of illness.

It should also be taken into consideration how the individual's willingness to pay for health risk reductions varies with the type of health threat [Cameron et al., 2010; 
Chestnut et al., 2012]. These studies provided the various VSLs that were mainly focused on systematic differences in WTP for health risk reductions across different types of health threats including various types of cancers, chronic heart diseases, respiratory disease, diabetes, etc., and the results suggested that the marginal disutility from each type of health state differs across various categories of illness as shown in Table B1.

Table B1. Mean VSLs for a 1 in 1,000,000 risk reduction across different types of health risks [Cameron et al., 2010] adjusted for modern inflation as on (\$2016)

\begin{tabular}{|l|c|c|c|}
\hline \multicolumn{1}{|c|}{ Profile } & \multicolumn{3}{|c|}{ Sudden Death Now } \\
\hline \multicolumn{1}{|c|}{ Age now } & $\mathbf{3 0}$ & $\mathbf{3 5}$ & $\mathbf{6 0}$ \\
\hline Health Threat & 9.30 & 9.80 & 8.30 \\
\hline Heart attack & 9.20 & 9.70 & 8.20 \\
\hline Breast Cancer & 8.80 & 9.40 & 7.80 \\
\hline Prostate Cancer & 8.30 & 8.70 & 7.20 \\
\hline Colon Cancer & 5.00 & 5.50 & 3.90 \\
\hline Lung Cancer & 1.07 & 1.09 & 0.20 \\
\hline Skin Cancer & 0.50 & 0.40 & 0.04 \\
\hline Stroke & 7.10 & 7.60 & 6.10 \\
\hline Respiratory Disease & 0.40 & 0.30 & 0.03 \\
\hline Traffic accident & 1.20 & 0.90 & 0.07 \\
\hline Diabetes & 5.90 & 3.80 & 0.30 \\
\hline Alzheimer's disease & 0.20 & 0.90 & 2.50 \\
\hline
\end{tabular}

${ }^{a}$ All values expressed in millions (\$2016)

Note: All the tabular VSL values mentioned here are derived by using one in a million risk scenarios.

From the values in Table B1, the VSL simulated for cancer caused by smoking shows the highest value, which refers to the people's attitude that people who smoke are more willing to pay for reducing the risk of cancer. The second highest VSL estimated in the above table is for the risk reductions caused by heart-related issues (e.g., heart disease, heart attack). The study supports the notion that willingness to pay to reduce 
motor vehicle mortality risks is less than that for similar risks from heart diseases, stroke disease, and several types of cancers. This suggests that the types of health threats targeted should be taken into consideration.

\section{Appendix B- References}

Hökby, S. and Söderqvist, T. Environmental and Resource Economics (2003) 26: 361. doi: 10.1023/B:EARE.0000003581.97411.75 